\title{
Práticas de escrita na \\ universidade: vozes de autoria no gênero resenha
}

\author{
Dalve Oliveira Batista-Santos" \\ Dimas Henrique Pereira de Oliveira Silva"
}

\section{Resumo}

A pesquisa em questão tem por objetivo analisar a escrita dos alunos do curso de Letras de uma universidade pública do estado do Tocantins, a fim de examinar a forma como eles se assumem autores dos textos produzidos na disciplina de Morfologia do Português, no gênero textual resenha. Esse gênero está na ordem do argumentar, permitindo ao resenhista agir, tanto em descrição da obra resenhada, quanto em avaliação, ora em um extremo ora em outro. Dessa forma, a presente pesquisa apresenta-se situada no paradigma de pesquisa qualitativa, de natureza documental, com uma concepção transgressiva de Linguística Aplicada. Os resultados mostraram como os acadêmicos, citam e fazem referências aos textos por meio de elementos linguísticos-discursivos. Ainda, constatamos a funcionalidade dos adjetivos, advérbios e verbos de expressarem posicionamentos do resenhista em relação ao texto-base se dá em correspondência com os verbos selecionados na resenha analisada.

Palavras-chave: Interacionismo Sociodiscursivo; Novos Estudos do Letramento; autoria.
* Doutora e mestra em Linguística Aplicada e Estudos da Linguagem pela Pontifícia Universidade Católica de São Paulo (PUC-SP). Professora Adjunta na Universidade Federal do Tocantins - UFT, atuando na graduação em Letras - Língua Portuguesa e Respectivas Literaturas e no Programa de Mestrado em Letras (PPGLetras), no Câmpus de Porto Nacional. É membro do grupo de pesquisa Práticas de Linguagens - PLES, nas linhas de pesquisa Escrita Acadêmica na Formação do Professor e Práticas de linguagem: leitura; escrita; análise linguística e, no Grupo de Estudos da Indeterminação e da Metáfora (GEIM), na linha de pesquisa Linguagem e Educação da PUC/SP. Licenciada em Letras - Língua Portuguesa e Respectivas Literaturas. Especialista em Ensino da Língua Portuguesa e Literaturas. Atua nas seguintes áreas: 1) Gêneros textuais e ensino de língua materna na perspectiva do ISD; 2) Práticas de letramento e ensino; 3) Letramento Acadêmico: Leitura e escrita na Universidade; 4) Formação do professor de Língua Portuguesa.

** Mestrando em Letras pelo PPG-Letras da Universidade Federal do Tocantins (UFT), graduado em Letras: Língua Portuguesa e Respectivas Literaturas pela mesma instituição. Foi bolsista por dois anos do Programa Institucional de Bolsas de Iniciação Científica (PIBIC), sediado pelo Conselho Nacional de Desenvolvimento Científico e Tecnológico $(\mathrm{CNPq})$. É pesquisador do grupo de pesquisa Práticas de Linguagens - PLES, na linha de pesquisa Práticas de linguagem: leitura; escrita; análise linguística, no Grupo de Estudos da Indeterminação e da Metáfora (GEIM), na linha de pesquisa Linguística Aplicada: Texto, Discurso e História da PUC/SP. Tem experiência na área de Linguística, com ênfase em Linguística Aplicada, atuando principalmente nos seguintes temas: Práticas de letramento e ensino; Letramento Acadêmico: Leitura e escrita na Universidade e Gêneros Textuais.

Data de submissão: abr. 2021 - Data de aceite: jul. 2021 http://dx.doi.org/10.5335/rdes.v17i2.11350 


\section{Introdução}

As práticas de escrita no ambiente acadêmico, de acordo com algumas pesquisas, apresentam-se como uma atividade complexa (BATISTA-SANTOS, 2017; 2019) e muitas vezes laboriosa (MARCUSCHI, 2008), o que dificulta o desenvolvimento significativo dos letramentos (LEA; STREET, 2014) dos envolvidos nesta modalidade de ensino. Para Lea e Street (2014) o desenvolvimento do letramento dos sujeitos ocorre a partir do domínio de diversos gêneros textuais (BRONCKART, 2009) que circulam nessa esfera acadêmica.

Diante desse contexto de complexidade das atividades escritas, é pertinente afirmar que um dos gêneros textuais que é solicitado pelos docentes efetivamente nessa esfera de produção é o gênero resenha. Isso se dá devido às suas características composicionais, bem como sua finalidade, uma vez que no referido gênero, é permitido ao autor, ou resenhista, tanto sumarizar o conteúdo estudado, quanto argumentar criticamente sobre o mesmo. Assim, esse artefato cultural (BRONCKART, 2009) configura-se uma importante ferramenta de estudos, pois possibilita a legitimação do posicionamento do resenhista.

Considerando a finalidade do gênero resenha, Dolz e Schneuwly (2004, p. 60) ao teorizarem sobre ele, classificaram-no como um dos "gêneros da ordem do argumentar", pois, como afirma Novaes
(2008), esse gênero apresenta características tanto de descrição quanto de avaliação, agindo de forma ambígua, ora em um extremo, ora em outro.

Dessa forma, ponderando a riqueza estilística (características composicionais), o plano do conteúdo e a finalidade do gênero resenha, a presente pesquisa tem como objetivo central investigar os modos particulares dos estudantes do curso de Licenciatura em Letras-Língua Portuguesa e Respectivas Literaturas, de uma universidade federal assumirem-se como autores na produção de gêneros acadêmicos, em específico o gênero textual resenha.

Com uma abordagem qualitativa (DENZIN; LINCOLN, 2006), de natureza documental e assumindo uma concepção de linguagem dialógica (BAKHTIN, 2006), o presente estudo insere-se no campo da Linguística Aplicada (doravante LA). Assim, utilizando de uma perspectiva transgressiva de LA (PENNYCOOK 2006), propomos um possível diálogo entre os Novos Estudos dos Letramentos (NEL) e o Interacionismo Sociodiscursivo (ISD) para embasar as análises que aqui serão realizadas.

\section{Letramentos acadêmicos}

Antes de apresentarmos a perspectiva em questão e a forma que a assumimos na presente pesquisa é importante salientar que, de acordo com Batista-Santos (2018) a escrita, nos contextos 
acadêmicos, tem demonstrado ser foco de pesquisas, e como resultado vem trazendo reflexões significativas

[...] na busca por uma compreensão crítica das práticas de leitura e escrita que circulam na esfera acadêmica, com a finalidade de sanar as lacunas que dificultam o desenvolvimento do letramento acadêmico dos sujeitos envolvidos (BATISTA-SANTOS 2018, p. 57).

De modo geral, os estudos dos letramentos acadêmicos referem-se às práticas sociais e específicas de leitura, escrita e oralidade, e muito embora haja pesquisadores que utilizem a terminologia "letramentos acadêmicos" para se referirem às práticas sociais de leitura e escrita no Ensino Superior (a saber, LEA; STREET, 2014; OLIVEIRA, 2016; BATISTA-SANTOS, 2017; 2018), utilizamos o conceito de letramentos acadêmicos de acordo com Lea e Street (2014, p. 491), que postula que os letramentos acadêmicos estão "envolvidos no aprendizado acadêmico dentro e fora dos contextos acadêmicos". Tais práticas sociais, segundo os referidos autores, podem iniciar (ou não) no ambiente acadêmico. Existem muitos gêneros textuais (artigo, resumo, resenha) que, de maneira equivocada, são considerados como único meio de circulação na universidade.

Dessa forma, de maneira oposta temos os gêneros textuais multimodais, que em sua maioria circulam socialmente fora das universidades, porém, acreditamos que deveriam ser trabalhados nessa esfera, uma vez que na academia, há alguns anos, se enfatiza a importância de trabalhar com esses artefatos culturais, dado sua importância enquanto ferramenta de ensino.

No caso específico da resenha, que é nosso objeto de estudos, pode ocorrer que ela circule fora do ambiente acadêmico, a saber as resenhas de livros e filmes, todavia, o seu maior funcionamento se dá na esfera social discursiva da academia. Importa dizermos que cada esfera social de utilização da linguagem, requer características específicas e engajadas do gênero utilizado, isto é, o resumo escolar possui características específicas que o pode diferenciar do resumo acadêmico.

Tendo postulado a forma com a qual entendemos os letramentos acadêmicos é importante salientarmos como tal perspectiva estabelece seus modelos de análises, modelos que usamos com o fito de alcançar os objetivos antes traçados. Em textos como: Street (2010a; 2010b); Lea e Street (2014); Batista-Santos (2017) e Batista-Santos e Silva (2017) é sugerido pelos NEL três modelos de análise para se avaliar questões referentes a escrita, eles são: modelo de habilidades de estudo (compreende os saberes linguísticos apropriados pelos sujeitos em sua trajetória acadêmica), modelo de socialização acadêmica (compreende as estratégias de utilização dos saberes adquiridos nas diversas esferas sociais. Aqui o professor é fundamental no que se refere a inser- 
ção dos sujeitos nas práticas letradas) e modelo dos letramentos acadêmicos ${ }^{1}$.

Dessa forma, de acordo com Lea e Street (2014), os letramentos acadêmicos

[...] tem relação com a produção de sentido, identidade, poder e autoridade; coloca em primeiro plano a natureza institucional daquilo que conta como conhecimento em qualquer contexto acadêmico específico. [..] considera os processos envolvidos na aquisição de usos adequados e eficazes de letramento como mais complexos, dinâmicos, matizados, situados, o que abrange tanto questões epistemológicas quanto processos sociais incluindo: relações de poder entre pessoas, instituições e identidades sociais (LEA; STREET, 2014, p. 479).

Coadunando com o posicionamento de Lea e Street e os NEL, defendemos uma perspectiva ideológica, bem como uma concepção crítica e reflexiva das práticas de escrita, uma vez que o modelo dos letramentos acadêmicos visa as relações de poder estabelecidas nas práticas de letramento dos sujeitos. Assim, compreendemos que desenvolver a competência de escrita, além de ser uma atitude necessária para atuação profissional enquanto docente, é também um ato político, e muito embora seja o esperado do aluno o desenvolvimento de tais competências, o fenômeno acontece em instâncias não observáveis, o que vai ao encontro de outro conceito dos NEL, o de práticas de letramentos.

Logo, na constituição dos NEL dois conceitos são de extrema importância para essa discussão, o de eventos de le- tramentos e o de práticas de letramentos. Tal importância dá-se uma vez que no fenômeno estudado encontram-se ambos os acontecimentos. O primeiro, eventos de letramentos, refere-se a um conceito desenvolvido por Shirley Heath, na década de 80 nas primeiras pesquisas dos estudos do letramento. Na referida época, Heath definiu o acontecimento como "todas as situações em que a escrita constitui parte essencial para fazer sentido em uma dada ocasião específica" (HEATH, 1982, p. 50), que é o caso das aulas de Morfologia do Português, que fazem parte do objeto de estudo da presente pesquisa. Na disciplina em questão um dos objetos avaliativos é a produção de uma resenha do livro Teoria Lexical, que é parte constituinte dos conteúdos estudados na disciplina.

Vejamos agora o segundo conceito, que por sua vez tem sua origem um pouco após o primeiro que antes foi apresentado, surge dos estudos de Brian Street, pesquisador que em vários dos seus estudos acerca do letramento utilizou a metodologia de pesquisa etnográfica ${ }^{2}$, e, chegou à conclusão de que os eventos de letramentos são os acontecimentos observáveis, enquanto as práticas de letramentos são aqueles acontecimentos que são impossíveis de detectar "sentados sobre um muro, com uma câmera de vídeo, observando o que estiver acontecendo" (STREET, 2003, p. 8). Para o autor, surgia mais uma questão referente às pesquisas etnográficas: “[...] temos 
que começar a falar com as pessoas, a ouvi-las e a associar a sua experiência imediata a outras coisas que possam também estar fazendo" (STREET, 2003, p. 8), ou seja, para o conhecimento de tais práticas há uma exigência maior dos pesquisadores, tudo isso por meio de um maior envolvimento com o objeto de pesquisa, com a sua participação em contexto reais de letramentos.

Tais conceitos apresentam-se importantes para a pesquisa em questão, tendo em vista que, tanto os eventos quanto as práticas de letramentos ocorrem no caso estudado. Os eventos de letramento nos acontecimentos das aulas e atividades oficiais e as práticas de letramentos nos acontecimentos não observáveis surgidos dos eventos de letramento. E como esta investigação não trata apenas de uma perspectiva teórica sobre as práticas e eventos de letramento, mas que busca fazer essas inferências em um gênero textual, apresentamos na seção subsequente a filiação teórica escolhida para analisarmos o gênero resenha.

\section{Gênero textual e tipos de vozes: desdobramentos na perspectiva do ISD}

O estudo dos gêneros, como afirmou Marcuschi (2008, p. 147), "não é novo, mas está na moda", pois nas últimas décadas, surgiu uma efervescente quantidade de pesquisas que problematizam tais questões. Um exemplo disso são as publicações de documentos oficias que trazem uma abordagem do ensino de línguas por meio dos gêneros textuais (BRASIL $^{3}, 2017$ ).

De acordo com vários pesquisadores (BRONCKART, 2009; MACHADO; ABREU-TARDELLI; CRISTÓVÃO, 2005; MARCUSCHI, 2008), os estudos sobre os gêneros iniciaram na Grécia antiga, foram retomados por Mikhail Bakhtin na Rússia Soviética, esquecidos por um tempo (por questões políticas) e mais uma vez retomados ao final da década de 70 e início da década de 80 do século XX. Bakhtin (2006, p. 290, grifo nosso), quando se refere à utilização da língua nas múltiplas atividades humanas, assevera que

Todas as esferas da atividade humana, por mais variadas que sejam, estão sempre relacionadas com a utilização da língua. Não é de surpreender que o caráter e os modos dessa utilização sejam tão variados como as próprias esferas da atividade humana [...] A utilização da língua efetua-se em forma de enunciados (orais e escritos), concretos e únicos, que emanam dos integrantes duma ou doutra esfera da atividade humana. $\mathrm{O}$ enunciado reflete as condições específicas e as finalidades de cada uma dessas esferas [...] cada esfera de utilização da língua elabora seus tipos relativamente estáveis de enunciados, sendo isso que denominamos gêneros do discurso.

Postulamos, todavia, que não foram apenas os estudos bakhtinianos que trouxeram contribuições para os estudos sobre gêneros, uma das correntes teóricas, 
que fundamenta essa parte da pesquisa (o trabalho com gêneros) que em muito acrescentou a tais estudos, é o Interacionismo Sociodiscursivo (doravante ISD).

O Interacionismo Sociodiscursivo, de acordo com Machado (2005), é uma teoria que se filia à psicologia da linguagem por se embasar no interacionismo social de Vygotsky (fundamentação teórica central). É um projeto teórico-metodológico de abordagem marxista, por isso age dialeticamente no que se refere aos fenômenos sociais e psicológicos, coadunando com a tese de que "as propriedades específicas das condutas humanas são o resultado de um processo histórico de socialização, possibilitado especialmente pela emergência e pelo desenvolvimento dos instrumentos semióticos" (BRONCKART, 2009, p. 21). Assim, as ações como linguagens verbais e não verbais, nessa perspectiva, ganham privilégio ao serem analisados.

Partindo desses pressupostos, os gêneros textuais têm uma grande importância em tal abordagem, uma vez que "é impossível se comunicar verbalmente a não ser por algum gênero, assim como é impossível se comunicar verbalmente a não ser por algum texto. Em outros termos, partimos da ideia de que a comunicação verbal só é possível por algum gênero textual" (MARCUSCHI, 2010, p. 22, grifo do autor). No que se refere à noção de gêneros textuais, de acordo com Machado, Abreu-Tardelli e Cristóvão (2009, p. 97):
É equivalente à noção bakhtiniana (Bakhtin, 1953, p. 279) de gênero do discurso, segundo a qual as diferentes esferas das atividades humanas, sócio-histórica, elaboram tipos relativamente estáveis de enunciados, os gêneros de discurso, que se caracterizam por apresentarem conteúdos, estruturação, relações entre os interlocutores e estilo específicos.

Tendo postulado a noção de gênero assumida, ressaltamos que para Bronckart (2009) um texto é organizado por meio de um folhado no qual se constitui de três camadas superpostas, tais camadas são: a infraestrutura geral do texto, os mecanismos de textualização e os mecanismos enunciativos. Consideramos importante abordar essas três camadas, todavia, explicitando que embora todas elas componham o texto, tratamos, pois, mais diretamente com duas delas, a primeira (infraestrutura geral do texto) e a última (mecanismos enunciativos).

Sobre a infraestrutura geral do texto pode-se dizer que se encontram o plano geral, que se refere ao conjunto do conteúdo temático, e os tipos de discursos, que são segmentos encontrados no texto, podendo ser segmentos de discursos teóricos, segmentos de narração e segmentos de discursos interativos. Também, podemos encontrar as articulações entre tipos de discurso. A noção de sequência ou como coloca Adam ${ }^{4}$ (1992) sequencialidade, que se refere ao que no Brasil é mais conhecido com o nome de tipologia textual ${ }^{5}$, essas são: descritiva, explicativa, argumentativa, narrativa, injuntiva e dialogal. 
A respeito dos mecanismos de textualização, Bronckart (2009), elenca três: mecanismos de conexão (conjunções, advérbios, locuções adverbiais, grupos preposicionais e segmentos de frases), de coesão nominal (hiperônimo, expressões definidas, mesmo item lexical, etc.) e de coesão verbal (tempos verbais). Sobre os mecanismos enunciativos há o posicionamento enunciativo e vozes, nos quais se encontram a voz do autor empírico, as vozes sociais e as vozes de personagens, bem como as modalizações que podem ser: lógicas, apreciativas e pragmáticas.

No que se refere aos mecanismos enunciativos discorrermos sobre os tipos de vozes, uma vez que a autoria e os posicionamentos autorais são o foco central da presente pesquisa. E, como a proposta teórico-metodológica do ISD anuncia um diálogo com os conhecimentos acerca do agir humano, os apontamentos de Bronckart (2009) sobre as vozes que emanam do texto têm sua base constitutiva no conceito de "Polifonia", de Bakhtin (2006) e para que se chegue nos mecanismos enunciativos tratamos do surgimento desse estrato. Alguns dos conceitos do filósofo russo estão em consonância com os do ISD, como é o caso das discussões acerca das vozes sociais, bem como o fenômeno de autoria, como veremos a seguir.

Para Bronckart (2009), o autor é aquele cuja responsabilidade do texto é atribuída, que pode ser de exclusividade sua, ou pode ser explicitamente de outrem. Nessa perspectiva, como afirma Costa (2012, p. 31) "o autor seria aquele que está na origem do texto, pelo qual é responsável, porém não seria o único responsável pelo enunciado". Logo, na discussão sobre autoria: "São as vozes que assumem a responsabilidade do que é enunciado" (COSTA, 2012, p. 31), portanto, na perspectiva de Bronckart (2009), as vozes podem ser subdivididas de três formas: a voz do autor, as vozes sociais e as vozes das personagens.

No que se refere à primeira categoria de voz, Bronckart (2009) define como autor aquele cuja ação está na origem do texto, já as vozes sociais são aquelas que emanam de

[...] procedentes personagens, grupos ou instituições sociais que não intervêm como agente no percurso temático de um segmento de texto, mas são mencionados como instâncias externas de avaliação de alguns aspectos desse conteúdo (BRONCKART, 2009 p. 327).

No caso específico desta pesquisa, as vozes sociais seriam aquelas atribuídas pelo resenhista ao autor da obra resenha$\mathrm{da}$, ou à própria obra, como por exemplo: "Com seu estilo linguístico, Margarida Basílio nos passa um livro que podemos levar pra vida todo como um presente de conhecimento e aprendizado que podemos levar para toda a vida acadêmica" (trecho da resenha analisada de número 2 ).

No tocante às vozes das personagens, podemos afirmar que estas referem-se 
àquelas entidades humanizadas que estão implicadas como agentes das ações que constituem o conteúdo temático de um segmento do texto. Esses agentes podem ser as personagens principais de um conto, animais e etc. Dessa forma, podemos classificar as vozes supracitadas como as responsáveis para a constituição da autoria-dialogal de um texto.

Consideramos pertinente, entretanto, afirmar que para os pesquisadores do ISD só é possível "a compreensão e produção dos textos” (CRISTOVÃO, 2005) se o actante $^{6}$ desenvolver algumas capacidades de linguagem (CRISTOVÃO, 2005; DOLZ; PASQUIER; BRONCKART, 1993; BRONCKART, 2009). E de acordo com Dolz e Schneuwly (1998; 2004) essas capacidades são: capacidades de ação, que dizem respeito à capacidade que o sujeito tem de se adaptar às características da situação enunciativa e ao coenunciador; as capacidades discursivas, que dizem respeito às faculdades de mobilização discursiva e as capacidades linguístico-discursivas, que estão relacionadas aos

[...] conhecimentos e/ou representações que um indivíduo constrói sobre as operações e os recursos de linguagem necessários para a produção ou compreensão de um texto (CRISTOVÃO, 2013, p. 368 apud DOLZ; SCHENUWLY 1998).

A primeira operação, de acordo com Muniz-Oliveira (2005, p. 113), diz respeito ao "efeito que o autor resenhado estaria buscando produzir no destinatário, efeito este que não é dado diretamente por seu texto, mas que resulta de uma interpretação do resenhador". Em outras palavras, esses efeitos de sentidos não são realizados de maneira clara, antes estão relacionados às interpretações do resenhista.

No que se refere às operações discursivas, essas, de acordo com Muniz-Oliveira (2004; 2005), podem ocorrer de maneiras diferentes. A primeira forma de operação discursiva encontrada é a que remete a um plano global do texto (MUNIZ-OLIVEIRA, 2004). Esta forma operacional encontra-se em todas as resenhas corpus pesquisado (R1: "O livro inicia com mistérios que levam o leitor a várias reflexões"; R2: "A autora inicia o primeiro capítulo falando sobre como se formam as palavras"). $O$ verbo iniciar, por exemplo, faz a inferência de que existe, na obra resenhada, um plano global que mostra a ideia de sequencialidade, que por sua vez se concretiza em início, meio e fim. Sendo esse plano global estabelecido pelo autor resenhado (MUNIZ-OLIVEIRA, 2005).

Assim, podemos afirmar sobre as operações discursivas que

O resenhador, na verdade, está interpretando possíveis operações do autor resenhado referentes à mobilização de conteúdos, ao modo de abordá-los e organizá-los, já que o que se descreve são operações do autor resenhado que não são, quase que como regra geral, diretamente explicitadas no texto. Desse modo, essa descrição resulta da interpretação das operações desenvolvidas pelo autor resenhado, materializadas em formas textuais (MUNIZ-OLIVEIRA, 2005, p. 119, grifos da autora). 
Há ainda um terceiro caso de operações, que são chamadas de operações linguístico-discursivas. Estas, por sua vez, são usadas pelo resenhador "quando ele interpreta a relevância temática, a articulação dos segmentos do texto, o estabelecimento de relações com outras vozes” (MUNIZ-OLIVEIRA, 2005, p. 123). É, portanto, um procedimento que, além de revelar os sentidos do verbo, também contribui para o desenvolvimento dos letramentos acadêmicos dos alunos, uma vez que ao realizar esse procedimento, o resenhista estará detectando as ocorrências polifônicas no texto resenhado, sejam elas para discordar de uma tese levantada por outrem, ou para ratificar posicionamentos assumidos pelo autor da obra resenhada.

As operações linguístico-discursivas designam, então, coerências temáticas e pragmáticas, aquelas, que de acordo com Muniz-Oliveira (2005), dizem respeito ao estabelecimento de coerência acerca do tema, se concretizando por meio dos verbos de citação, enquanto essas, dizem respeito aos "diferentes verbos que se referem às operações de inserção de vozes" (MUNIZ-OLIVEIRA, 2005, p. 120), sendo os exemplos acima destacados pertencentes ao domínio da coerência pragmática.

\section{Diálogos possíveis entre o ISD e os novos estudos do letramento}

Recuperando a discussão sobre os NEL, tornam-se mais claros os pontos de contato - sem nenhuma pretensão de esgotar o tema - entre as questões circunscritas na compreensão desse campo de conhecimento e as formulações provenientes do ISD. Elencamos como justificação de tais proposições a compreensão de língua como prática social trazida pelas duas perspectivas teóricas. Outro ponto que carece nossa atenção refere-se ao lugar assumido pelo sujeito nas práticas linguageiras, pois, ao elencar o sujeito, bem como o contexto de produção para se analisar os diversos gêneros textuais (movimento esse que faz o ISD) abrem-se as possibilidades para um diálogo com o modelo ideológico de letramento, o que nesta pesquisa se concretiza no modelo de letramentos acadêmicos.

Tal colocação efetiva-se porque há interesses em comum por ambas as perspectivas. Comecemos, pois, com a definição do que seria o ISD, que de acordo com Bronckart (2009) o interacionismo sociodiscursivo é um quadro teórico que

[...] leva a analisar as condutas humanas como [...] ações situadas, cujas propriedades estruturais e funcionais são, antes de mais nada, um produto da socialização (BRONCKART, 2009, p. 13, grifos nossos). 
Já os NEL referem-se a práticas letradas, sejam elas de leitura, escrita ou oralidade, socialmente situadas. Temos, portanto, um primeiro interesse em comum, as práticas linguageiras socialmente situadas.

Outra proposição que elencamos está estritamente ligada ao contexto de produção. Como pontuado na seção anterior que tratamos da forma de se analisar os gêneros textuais mediante a perspectiva do ISD, a evocação do contexto social de produção torna-se uma das grandes contribuições para os estudos sobre gêneros, uma vez que os estudiosos do referido quadro teórico não concebem a interpretação, análises e até o ensino dos gêneros sem os seus referidos contextos de produção. Nos NEL há também uma atribuição de importância aos mesmos como podemos ver em Kleiman (2008, p. 491, grifos nossos):

De fato, o "modelo ideológico de letramento", descrito por Street (1984), ao levar em conta as situações sociais em que os textos são lidos e produzidos, assim como os valores e as representações a eles atribuídos, acaba destacando os aspectos socioculturais e históricos das práticas de uso da língua escrita e mostrando a necessidade de estudá-las a partir da reconstrução da história e das culturas locais. Seriam os contextos em que as práticas são mobilizadas os que nos mostram as diversas orientações de uso da linguagem, segundo as demandas, objetivos, metas de leitura e escrita das diversas situações de comunicação, assim como das relações, objetivos e necessidades dos participantes dessas situações.
O que torna essa proposição como sendo um interesse interligado à proposição anterior, uma vez que, para que ambas as perspectivas teóricas se interessam pelas ações linguageiras socialmente situadas, isto é, ao levarmos em conta as situações de produção e utilização dos gêneros textuais, bem como que a realidade fundamental da língua é a interação verbal, estamos ratificando que as práticas linguageiras se materializam por meio de enunciados concretos, que são produzidos por sujeitos socio-historicamente situados.

$\mathrm{O}$ último aspecto que elencamos, $\mathrm{e}$ que proporciona um diálogo entre as referidas perspectivas teóricas, é que para o desenvolvimento dos letramentos é necessário o suporte de diversos gêneros textuais. Elencamos esse diálogo com o apoio teórico de Kleiman (2010, p. 379):

\begin{abstract}
A alfabetização é uma prática de letramento que pode envolver diferentes estratégias (reconhecimento global da palavra, reconhecimento de sílabas, leitura em voz alta, leitura silenciosa), diversos gêneros (cartilhas, exercícios, imagens, notícias, relatos, contos, verbetes, famílias de palavras), diferentes tecnologias (lápis, caneta, papel, quadro negro, giz, lousa branca, pincel atômico, livro, tela e teclado).
\end{abstract}

Ou seja, desde a chegada dos alunos na escola já é exigido o uso de diversos gêneros textuais. A pesquisa de Kleiman (2010) tratou do diálogo do desenvolvimento dos letramentos em conjunto com a prática de letramento que é a alfabeti- 
zação, mas não paramos apenas com esse diálogo, trazemos à guisa das discussões Lea e Street (2014), que ao teorizar sobre os modelos de análises de escrita sugere, ainda no segundo modelo, o de socialização acadêmica, que o aluno concebe a escrita por meio de uma "aculturação" dos "discursos e gêneros" acadêmicos, aprendidos em diversas práticas sociais.

E mesmo acreditando que o ideal é o modelo dos letramentos acadêmicos, afirmamos que "Os três modelos não são mutuamente exclusivos; ao contrário, são sobrepostos. Todos eles poderiam ser aplicáveis a qualquer contexto acadêmico" (LEA; STREET, 2014, p. 479). Assim, a necessidade dos envolvidos nas práticas letradas do ambiente acadêmico de lidar com diversos gêneros textuais faz com que haja um interesse em comum entre os quadros teóricos: o desenvolvimento de capacidades de linguagem que ultrapassam o mero conhecimento linguístico e estilístico de determinado gênero, todavia esse desenvolvimento contempla as relações de poder e constituição de identidade.

Isso se configura, nesta pesquisa, da seguinte forma: de que forma a produção de um texto pertencente ao gênero textual resenha ajuda na constituição dos letramentos acadêmicos? Como o aluno envolvido nesse processo se coloca no texto por si produzido? Como a identidade dessa autoria é assumida? $\mathrm{O}$ gênero em questão oferece alguma ajuda para que esses escritores se coloquem como autores em suas produções ou é permissivo à negação da sua identidade? Dito isso, na próxima apresentamos o percurso utilizado para o desenvolvimento da pesquisa e análise dos dados.

\section{Análises e resultados dos dados}

O corpus da presente pesquisa é composto por cinco produções textuais do gênero resenha. Tais produções foram elaboradas na disciplina de Morfologia do Português, que integra o $3^{\circ}$ período do curso de Letras, de uma universidade pública do estado do Tocantins.

O primeiro procedimento realizado foi o de escolha do período e da turma para as análises de suas produções. Colocamos que o aluno de tal instituição, especificamente, no terceiro período do curso acima mencionado, não é mais 'iniciante' nas práticas de escrita (no tocante às práticas de letramento acadêmico), em virtude de ter passado por diversas disciplinas que trabalham o desenvolvimento, tanto da competência leitora quanto escritora e, especificamente, por já ter cursado a disciplina de Escrita Acadêmica.

O segundo procedimento foi a seleção das resenhas, tendo em vista que os textos produzidos, a pedido da docente, teriam de conter as características que compõem tal gênero. Para um olhar menos atencioso, esse procedimento pode pa- 
recer desnecessário em virtude de que os alunos envolvidos/matriculados no ensino superior "tecnicamente" já possuem os conhecimentos necessários para a produção do gênero em questão, entretanto, na prática, não é o que vem acontecendo na realidade brasileira (para mais detalhes, conforme BATISTA-SANTOS, 2017).

Para a concretização dessa parte da pesquisa, tomamos como aporte teórico metodológico as obras de Machado, Lousada e Abreu-Tardelli (2004) e Motta-Roth e Hendges (2010), por acreditarmos que o diálogo entre tais autorias possa enriquecer as análises da presente pesquisa. Destacamos também que há diferenciações, no que acreditam os autores, acerca das características necessárias para a composição do gênero resenha.
Como asseveram Motta-Roth e Hendges (2010), por exemplo, o título ou a referência bibliográfica não se apresentam como necessários, ou obrigatórios, para a classificação de um texto como pertencente ao gênero resenha. $O$ que não vem a ocorrer na obra de Machado, Lousada e Abreu-Tardelli (2004), pois nela encontramos como característica necessária o título da obra para as resenhas que não pertencem ao ambiente acadêmico e a referência bibliográfica para os textos que circulam no ambiente acadêmico. Nós, todavia, propomos um diálogo ou junção entre as propostas, que se apresentará ao leitor a seguir, em forma de um quadro. Ressaltamos, pois, que esse quadro foi utilizado nas análises dos textos que compõem o corpus da pesquisa.

Quadro 1 - Características do gênero resenha

1 REFERENCIAL DA OBRA

a) referência da obra resenhada

ou

b) título da obra resenhada

2 CREDENCIAIS DO(A) AUTOR(A)

Passo 2 informar a formação e/ou área de atuação do(a) autor(a) da obra resenhada

\section{APRESENTAR A OBRA}

Passo 3 informar tópico geral do livro e/ou

Passo 4 definir o público-alvo

e/ou

Passo 5 dar referência sobre o autor e/ou

Passo 6 fazer generalizações

Passo 7 inserir o livro na disciplina

4 DESCREVER A OBRA

Passo 8 dar uma visão geral da organização do livro e/ou

Passo 9 estabelecer o tópico de cada capítulo e/ou

Passo 10 citar material extratextual

5 AVALIAR PARTES A OBRA

Passo 11 realçar pontos específicos

6 (NÃO) RECOMENDAR A OBRA

Passo 12a desqualificar/recomendar o livro

ou

Passo $12 \mathrm{~b}$ recomendar o livro apesar das falhas indicadas

Fonte: Adaptado pelos autores, baseado nas obras de Machado, Lousada e Abreu-Tardelli (2004) e Motta-Roth e Hendges (2010). 
Para a diferenciação dos textos analisados utilizamos o nome de "Resenhistas" seguidos dos números $1,2,3,4 \mathrm{e}$ 5. A ordem pré-dispostas às produções analisadas se dão por ordem alfabética e numérica, e não por outra valoração. Não consideramos o texto do Resenhista 1 mais importante que o do Resenhista 2 e vice-versa, eles se encontram dessa forma, pois alfabética e numericamente a letra e o número, que inicia o texto do
R1 (sigla referente ao primeiro Resenhista), se encontra em uma ordem anterior a do R2.

Assim, segue abaixo uma tabela constando as primeiras análises, que se efetivam em mostrar a classificação dos textos que compõem o corpus nas características do gênero em questão. A tabela mostra as ocorrências das características composicionais que o quadro acima elenca.

Quadro 2 - Características Composicionais

\begin{tabular}{|c|c|c|c|c|c|c|}
\hline \multicolumn{2}{|r|}{ Características composicionais } & $\mathrm{R} 1$ & $\mathrm{R} 2$ & R3 & $\mathrm{R} 4$ & $\mathrm{R5}$ \\
\hline \multirow{2}{*}{ Referencial da obra } & Referência da obra resenhada & $x$ & $\mathrm{x}$ & $x$ & & $\mathrm{x}$ \\
\hline & Título da obra resenhada & & & & $\mathrm{x}$ & \\
\hline Credenciais do (a) autor(a) & $\begin{array}{l}\text { Informar a formação e/ou área de atuação do(a) } \\
\text { autor(a) da obra resenhada }\end{array}$ & $\mathrm{x}$ & $\mathrm{x}$ & & $\mathrm{x}$ & $x$ \\
\hline \multirow{5}{*}{ Apresentar a obra } & Informar tópico geral da obra & & $\mathrm{x}$ & & $\mathrm{x}$ & $\mathrm{x}$ \\
\hline & Definir o público-alvo & & & & $\mathrm{x}$ & $\mathrm{x}$ \\
\hline & Dar referência sobre o autor & $x$ & $\mathrm{x}$ & $\mathrm{x}$ & $\mathrm{x}$ & $\mathrm{x}$ \\
\hline & Fazer generalizações & $\mathrm{x}$ & $\mathrm{x}$ & $\mathrm{x}$ & $\mathrm{x}$ & $\mathrm{x}$ \\
\hline & Inserir a obra na disciplina & & $\mathrm{x}$ & & $\mathrm{x}$ & $\mathrm{x}$ \\
\hline \multirow{3}{*}{ Descrever a obra } & Dar uma visão geral da organização da obra & & $\mathrm{x}$ & $\mathrm{x}$ & $\mathrm{x}$ & $\mathrm{x}$ \\
\hline & Estabelecer o tópico de cada capítulo & & $\mathrm{x}$ & & $\mathrm{x}$ & $\mathrm{x}$ \\
\hline & Citar material extratextual & & & & & \\
\hline Avaliar partes da obra & Realçar pontos específicos & $\mathrm{x}$ & $x$ & $x$ & $x$ & $\mathrm{x}$ \\
\hline \multirow{2}{*}{ (Não) recomendar a obra } & Desqualificar/recomendar o livro & $\mathrm{x}$ & & $\mathrm{x}$ & & $\mathrm{x}$ \\
\hline & Recomendar a obra apesar das falhas indicadas & & $x$ & & $\mathrm{x}$ & \\
\hline
\end{tabular}

Fonte: Elaborado pelos autores.

Diante do quadro, bem como das resenhas analisadas, constatamos a apropriação das principais características do gênero resenha. Os resenhistas atendem aos principais objetivos do gênero - descrever e avaliar; a linguagem empregada sinaliza a participação do produtor durante o movimento retórico de descrição, tornando esse movimento também avaliativo ("No terceiro capítulo a autora"; "Posteriormente no capitulo quatro"; "No capítulo cinco"; "No sexto capítulo"; "Mais adiante"; etc.) Tomemos como exemplo R5, considerando que os demais seguem a mesma composição: 
Para iniciar o livro, no primeiro capítulo, a autora aponta diferentes mistérios a respeito da formação da palavra, de modo que o primeiro enigma se resume em como essas novas formações podem ser aceitáveis ou não. Nesse caso, a autora faz uma breve certificação de que "muitas vezes não aceitamos certas palavras pelo simples fato de que já existem outras consagradas pelo uso" (p. 8), porém a mesma diz não ser suficiente essa explicação [...].

Com isso a autora traz outro ponto e mostra como a nossa língua é perfeita, ao invés de termos novas palavras para todos esses casos, o que multiplicaria a quantidade de palavra, apenas mudamos a classe ou fazemos um acréscimo semântico [...].

É um livro bastante abrangente e de leitura clara e informativa, útil para quem está iniciando o estudo de morfologia, e já possui um breve conhecimento a respeito, uma vez que explica sobre os assuntos que implicam na formação de palavras. Sendo assim, atende de maneira plausível as necessidades dos estudantes que se interessam por essa área do conhecimento linguístico, mas pode gerar dúvidas em um público leigo no que diz respeito a estudos morfológicos [...].

Outros fenômenos, entretanto, elencaremos nas análises aqui propostas no tocante às vozes de autoria. $\mathrm{O}$ primeiro fenômeno corresponde aos adjetivos, que constam tanto na descrição quanto na avaliação do texto-base (livro resenhado), ratificando os posicionamentos do texto-base. Na ação de descrever, a escolha das expressões: " $E$ de grande relevância e importância para o leitor"; "[...] não deixa de oferecer formas de análises menos complexas" resulta de uma interpretação e, ao mesmo tempo, concordância com o que é defendido no texto-base:
"É de grande relevância e importância para o leitor, a forma como Basílio constrói seu texto, visto que, o modo como detalha a teoria com exemplos, aumenta a chance de maior apreensão do conteúdo posto em estudo. Basílio se preocupa em evidenciar o ponto de vista da gramática tradicional, porém, não deixa de oferecer formas de análises menos complexas das formações de palavras, tornando a aprendizagem mais viável e produtiva".

De maneira patente, os adjetivos manifestam a valoração atribuída ao texto-base até mesmo em ações retóricas em que exista a predominância da tipologia descrição, como pode ser vislumbrada na apresentação e avaliação inicial, em que os adjetivos "importantes"; "diferentes"; "grande" referentes a ideias do texto-base, configuram uma postura crítica do resenhista.

Ainda, o emprego dos adjetivos "viável", "produtiva" e "menos complexas" expressam uma interação entre o texto-base e o resenhista (que é também leitor desse texto). O resenhista, dessa maneira, assume um papel ativo a partir do dizer do outro (texto-base) e, age criticamente e reflexivamente (refutando, concordando, reformulando) da discussão disponibilizada por esse dizer, discussão que é relevante para o ambiente do qual o resenhista é membro ativo.

O segundo fenômeno refere-se aos verbos que refletem ao que o resenhista atribui ao autor da obra resenhada, o que pode se configurar como pessoa 
(ex.: o/a autor/a), ou como obra (ex.: o livro). Assim, a utilização de elementos linguísticos é diversa e demonstra a subjetividade do resenhista, o qual não só exibe, como ratifica e promove o desenvolvimento/ampliação das ideias do texto resenhado, agindo como sujeito ativo de um discurso situado na esfera acadêmica, especificamente, no Curso de Letras. Isso pode ser confirmado se observarmos que o emprego dos verbos "constrói; levam; apresenta" também é resultado de uma interpretação que é influenciada pela concordância do resenhista com o texto-base, pois o verbo é posto em evidencia e inicia um pensamento ratificado pelo próprio resenhista.

R1: "O livro inicia com mistérios que levam o leitor a várias reflexões”; [...]“A autora define que os processos para ajudar na formação de palavras".

R2: "No capítulo seis, a autora apresenta outros processos de formação: Derivação regressiva"

R4: "O livro em questão, escrito pela professora Margarida Basílio, traz todo um arcabouço teórico"

R5: "É de grande relevância e importância para o leitor, a forma como Basílio constrói seu texto, visto que, o modo como detalha a teoria com exemplos, aumenta a chance de maior apreensão do conteúdo posto em estudo. Basílio se preocupa em evidenciar o ponto de vista da gramática tradicional, porém, não deixa de oferecer formas de análises menos complexas das formações de palavras, tornando a aprendizagem mais viável e produtiva". (grifos nossos)
$\mathrm{O}$ verbo definir, assim como o verbo levantar remetem, então, à ideia de exposição, pois o resenhista irá apresentar ao leitor conceitos, ou colocações, que ele considera importante. $\mathrm{O}$ que também se concretiza no segundo excerto da resenha do R1 e no excerto do R4, tendo em vista que o verbo trazer está ligando ao autor do texto resenhado, ou à sua obra, os conceitos que o resenhista considerou importante.

Em R5, por exemplo, notamos que a concordância com ideias do texto-base é reforçada, ainda, no período introduzido pelas conjunções, "porém" e pelo advérbio "menos" que, topicalizados, evidenciam a participação do resenhista no dizer do texto-base, tornando-se coprodutor desse dizer. Dessa forma, é relevante observarmos que o movimento de concordar e ratificar o texto-base corresponde um engajamento do resenhista com o conteúdo temático ultrapassando o simples objetivo de avaliá-lo.

R2: A maneira a que Basílio aborda esses temas aqui discutidos é de modo satisfatório para um bom entendimento do leitor, somente em alguns aspectos a autora aborda itens desnecessários, levando em consideração que os mesmos possuem nexos com o assunto do livro, porém, são apenas maneiras de exemplificar os conteúdos, tornando-se algo repetitivo e irrelevante.

R5: É de grande relevância e importância para o leitor, a forma como Basílio constrói seu texto, visto que, o modo como detalha a teoria com exemplos, aumenta a chance de maior apreensão do conteúdo posto em estudo. Basílio se preocupa em evidenciar 
o ponto de vista da gramática tradicional, porém, não deixa de oferecer formas de análises menos complexas das formações de palavras, tornando a aprendizagem mais viável e produtiva.

Notamos que o posicionamento do resenhista, frente ao texto resenhado, é crítico, realizando uma avaliação apreciativa que não se confunde com um cumprimento de protocolo. Tal posicionamento contribui para a constituição do letramento acadêmico, porque, primeiramente, ajuda aos envolvidos nessas práticas letradas a desenvolverem o senso crítico quando colocados 'contracenando' com outros conteúdos a serem estudados. E, em segundo lugar, porque a relação de identidade de autor que realiza posicionamentos autênticos é evidenciada. $\mathrm{Ou}$ seja, o resenhista participa ativamente da construção de sentidos e saberes, possibilitando assim o desenvolvimento do letramento acadêmico.

Por fim, nas resenhas analisadas, entretanto, a funcionalidade dos adjetivos, advérbios e verbos de expressarem posicionamentos do resenhista em relação ao texto-base se dá em correspondência com os verbos selecionados na resenha analisada. Podemos afirmar que os verbos usados em sua quase totalidade correspondem aos verbos performativos, e demonstram como o resenhista compreende e interpreta as ações linguageiras do autor do texto-base.

\section{Considerações finais}

O objetivo da presente pesquisa foi de investigar os modos particulares dos estudantes do curso de Licenciatura em Letras - Língua Portuguesa e Respectivas Literaturas, de uma universidade pública a se assumirem como autores na produção de gêneros acadêmicos, em específico o gênero textual resenha crítica. Para tanto, partimos do pressuposto de que o trabalho com os gêneros textuais, particularmente a resenha, como parte da formação universitária pode ser um elemento significativo e gerador da constituição do letramento acadêmico. Isso se dá devido às características composicionais, tendo em vista que o gênero em questão carrega uma essência dúbia, agindo em extremos de avalições e em extremos de descrição.

A ocorrência dos verbos, quando se trata de evocação ao autor da obra resenhada, que configuram a capacidade de ação, indicam posicionamentos de autonomia dos resenhistas frente aos textos resenhados. Uma vez que, de acordo com Muniz-Oliveira (2005, p. 88), as operações de ação dizem respeito ao "efeito que o autor resenhado estaria buscando produzir no destinatário, efeito este que não é dado diretamente por seu texto, mas que resulta de uma interpretação do resenhador." Outra ocorrência são os verbos e adjetivos de ações discursivas, esses têm por natureza a remissão ao 
plano global do texto. O que indica que, muito embora, os resenhistas tenham agido com autonomia frente aos textos resenhados, mantiveram a temática debater o texto em questão.

Diante do exposto, consideramos que a resenha permite ao resenhista, devido aos seus elementos constitutivos, que se coloque como autor, uma vez que a ele é consentido tecer considerações, que muitas vezes se configuraram como posicionamentos contrários à obra resenhada, mas também favoráveis, o que demonstra uma prática que desenvolve o letramento acadêmico (a autoria), tendo em vista que o aluno deixa de ser um sujeito passivo ao conteúdo trabalhado e passa a agir ativamente com a proposta de produção textual, de modo a relacionar o conhecimento adquirido com o ato de resenhar com o seu conhecimento adquirido durante sua vida.

Writing practices at the university: voices of authorship in thereview genre

\section{Abstract}

The present research aimed to analyze the writing of students of the Language undergraduate course of a public university in the state of Tocantins, in order to examine how these authors of the reviews produced in the discipline of Morphology of the Portuguese are assumed. Therefore, this research is situated in the paradigm of qualitative research, with a documentary methodological strategy and a transgressive conception of Applied Linguistics. The genre review is in the order of argument, allowing the designer to act, both in the description of the book reviewed, and in evaluation, sometimes at one end or at another. Thus, the results showed how academics, cite and make references to texts through linguistic-discursive elements. Furthermore, we note the functionality of adjectives, adverbs and verbs to express the reviwers' positions in relation to the base text is in correspondence with the verbs selected in the analyzed review.

Keywords: Sociodiscursive Interactionism; New Literacy Studies; authoring.

\section{Notas}

1 Como apenas o modelo dos letramentos acadêmicos é o foco da pesquisa em questão, indicamos ao leitor os textos antes citados.

2 Para mais detalhes,conforme Street (2003).

3 Base Nacional Curricular Comum.

4 Jean-Paul Bronckart, em suas teorizações, traz a linguística textual como suporte, o que justifica autores com Adam (1992) ganharem espaços em suas teorizações.

5 Isso se dá devido à importância do grande pesquisador Luiz Antônio Marcuschi (1946-2016), que ao teorizar sobre as tipologias textuais (2008; 2010) elenca cinco categorias: descritiva, injuntiva, expositiva, narrativa e argumentativa.

6 Utilizamos o termo "actante" de acordo com Cristóvão; Lopes (2011, p. 140), pois para as autoras: "No quadro do ISD, o termo actante é usado para designar qualquer pessoa implicada em um determinado agir. $\mathrm{O}$ termo ator é usado quando esse actante tem capacidades, motivos e intenções para o agir representado nos textos e o termo agente é usado para quando essas propriedades não são atribuídas ao actante”. 


\section{Referências}

BAKHTIN, M. Os gêneros do discurso. In: BAKHTIN, M. Estética da criação verbal. São Paulo: Martins Fontes, 2006.

BATISTA-SANTOS. D. O. Letramento acadêmico: representações de ingressantes acerca da escrita. Revista Trama. Volume 13 - Número 28 - 2017, p. 86 - 118. Disponível em: <http://e-revi ta.unioeste.br/index.php/trama/article/ view/15586-2017>. Acesso em:15-06-20.

BATISTA-SANTOS, D. O. Desenvolvendo o letramento acadêmico: práticas de leitura e escrita na universidade. Curso de Extensão Universidade Federal do Tocantins, Campus Porto Nacional. Porto Nacional, TO, 2019.

BATISTA-SANTOS. D. O. Prática dialógica de leitura na universidade: uma contribuição para a formação do leitor responsivo e do professor letrador. Tese de Doutorado. Programa de Estudos Pós-Graduados em Linguística Aplicada e Estudos da Linguagem. Pontifícia Universidade Católica de São Paulo, SP, Brasil, 2018.

BATISTA-SANTOS. D. O; SILVA, D. H. P. O. A escrita sob o olhar do aluno no Ensino Médio: representações e reflexões. Feira de Santana: A cor das Letras, v. 18, n. 3, p. 10-26, set./dez., 2017.

BASÍlIO, M. Teoria Lexical. 8. ed. São Paulo: Ática, 2007.

BRASIL. Base Nacional Comum Curricular: Educação Infantil e Ensino Fundamental. Brasília: MEC/Secretaria de Educação Básica, 2017.

BRONCKART, J. P. Atividades de texto e linguagem: por um Interacionismo sociodiscursivo. São Paulo: EDUC, 2009.

CRISTOVÃO, V.L.L. Gêneros textuais, material didático e formação de professores. Londrina: Signum: Estudos Linguísticos. p. 173-191. 2005. Disponível em: https://www.readcube.com/ articles/10.5433\%2F2237-4876.2005v8n1p173. Acesso em: 20-06-2020.
CRISTOVÃO, Vera Lúcia Lopes. Para uma expansão do conceito de capacidades de linguagem. In: BUENO, Luzia; LOPES, Maria Angela Paulino Teixeira; CRISTOVÃO, Vera Lúcia Lopes (orgs). Gêneros textuais e formação inicial: uma homenagem à Malu Matencio. Campinas: Mercado de Letras, 2013, p. 69-81.

COSTA, A. R. Mecanismos enunciativos: análise das vozes e modalizações em artigos científicos. Rios Eletrônica-Revista Científica da FASETE. ano 6 n. 6 dez. 2012. Recife: PE, 2012.

DENZIN, N. K; LINCOLN, I. O planejamento da pesquisa qualitativa: teorias e abordagens. Porto Alegre: Artmed, 2006.

DOLZ, J.; PASQUIER, A.; BRONCKART, J. L'acquisition des discours: emergence d'une competence ou apprentissagem de capacities langagières diverses? Etude de Linguistique Appliquée, n. 89, p. 25-35, 1993.

DOLZ, J.; SCHNEUWLY, B. Pour un enseignement de l'oral - initiation aux genres formels à l'école. Paris: ESF, 1998.

DOLZ, J.; NOVERRAZ, M.; SCHNEUWLY, B. Seqüências didáticas para o oral e a escrita: apresentação de um procedimento. In: $\mathrm{SCH}-$ NEUWLY, B.; DOLZ, J. (Orgs.) Gêneros orais e escritos na escola. Trad. Roxane Rojo e Glais Sales Cordeiro (Orgs).. Campinas: Mercado de Letras, 2004, p. 95-128.

HEATH, S. B. What no bedtime story means: narrative skills at home and school. Language in Society, v. 11, p. 49-76, 1982.

KLEIMAN. Â. B. Os estudos de letramento e a formação do professor de língua materna. Linguagem em (Dis)curso. v. 8, n. 3, p. 487517, set./dez. 2008.

KLEIMAN. Â. B. Trajetórias de acesso ao mundo da escrita: relevância das práticas não escolares de letramento para o letramento 
escolar. Florianópolis: Perspectivas. p. 375400, jul./dez. 2010. Disponível em: https://periodicos.ufsc.br/index.php/perspectiva/article/ view/2175-795X.2010v28n2p375 Acesso em: 20-06-2020.

LEA, M. R; STREET, B. V. O Modelo de "letramentos acadêmicos": teoria e aplicações. Filol. Linguíst. Port., São Paulo, v. 16, n. 2, p. 477493, jul./dez. 2014. Disponível em: <http https:// www.revistas.usp.br/flp/article/view/79407>. Acesso em: 20-06-2020.

MACHADO, A. R.; LOUSADA, E.G.; ABREU-TARDELLI, L.S.; Resenha. São Paulo: Parábola Editorial, 2004.

MACHADO, A.R. A perspectiva sociodiscursivo de Bronckart. In: MEURER, J.L; BONINI, A. \& MOTTA-ROTH, D. (Org.). Gêneros teorias, métodos e debates. São Paulo: Parábola Editorial, 2005, p. 237-259.

MACHADO, A.R.; ABREU-TARDELLI, L.A.; CRISTÓVÃO, V.L.L. (Orgs.). Linguagem e Educação: o ensino e a aprendizagem de gêneros textuais. Campinas: Mercado de Letras, 2009.

MARCUSCHI, L. A. Produção textual, análise de gêneros e compreensão. São Paulo: Parábola Editorial, 2008.

MARCUSCHI, L. A. Gêneros textuais: definição e funcionalidade. In: Dionísio, A. P.; Machado, A. R.; Bezerra, M. A. Gêneros textuais e ensino. São Paulo: Parábola Editorial, 2010.

MOTTA-ROTH, D.; HENDGES, G. R. Produção textual na universidade. São Paulo: Parábola Editorial, 2010.

MUNIZ-OLIVEIRA, S. Os verbos de dizer em resenhas acadêmicas. In: SIGNUM: Estudos da Linguagem, v8, n1, Universidade Estadual de Londrina (UEL), Londrina/PR, 2005, p. 103-129.

MUNIZ-OLIVEIRA, S. Os verbos de dizer em resenhas acadêmicas e a interpretação do agir verbal. Dissertação de Mestrado. Linguística Aplicada e Estudos da Linguagem. Pontifícia Universidade Católica de São Paulo, 2004. $132 \mathrm{p}$.
NOVAES, A. As muitas vozes de uma resenha crítica: por uma concepção interativo-dialógica da linguagem. São Paulo: ESP, 2008.

OLIVEIRA, E. F. O uso de verbos de citação em resenhas acadêmicas. In: FIAD, R. S. (Org.) Letramentos Acadêmicos: contextos, práticas, percepções. São Carlos: Pedro \& João Editores, 2016. 357 p.

PENNYCOOK, A. Uma linguística aplicada transgressiva. In: MOITA-LOPES, L.P (Org.). Por uma linguística aplicada indisciplinar. São Paulo: Parábola Editorial, 2006, p. 67-83.

SCHNEUWLY, Bernard; DOLZ, Joaquim. Gêneros orais e escritos na escola. Tradução e Roxane Rojo e Glaís Sales Cordeiro (Orgs.). Campinas, SP: Mercado de Letras, 2004. ().

STREET, B. V. Abordagens alternativas ao letramento e desenvolvimento: teleconferência Unesco Brasil sobre 'Letramento diversidade. King's College, Londres. Outubro de 2003.

STREET, B. V. Academic Literacies approaches to Genre. Belo Horizonte: RBLA, v. 10, n. 2, p. 347-361, 2010a.

STREET, B. V. Dimensões "Escondidas" na Escrita de Artigos Acadêmicos. Florianópolis: PERSPECTIVA, v. 28, n. 2, 541-567, jul./dez. 2010b. 